\title{
An Analysis of Cross-sectional Investment Portfolio with the Consideration of Risk and Return
}

\author{
Jingzheng Luo ${ }^{\dagger 1, \mathrm{a}}$, Jiasheng Guo ${ }^{\dagger 2, \mathrm{~b}}$, Hui $\mathrm{Li}^{\dagger 3, \mathrm{c}}$ \\ ${ }^{1}$ School of Statistics and Mathematics Central University of Finance and Economics, Beijing, China \\ ${ }^{2}$ School of Finance University of Delaware Newark, Delaware, USA \\ ${ }^{3}$ School of Finance and Accounting University of New South Wales Sydney, New South Wales, Australia \\ †These authors contributed equally.
}

\begin{abstract}
Recently, investors are requiring diversified options on the security investment, while the sudden incidents, such as the trade war and the pandemic of COVID-19, make the investment market more volatile and turbulent. Thus, this article will discuss how investors can make rational investment decisions by using the Markowitz's portfolio theory and its Mean-Variance Model in the U.S. investment market, in order to meet the requirement of diversification and to earn relatively stable profit. Therefore, the data spanning from 2016 to 2020 is used to provide investors with more reliable and comprehensive investment information. Meanwhile, a novel cross-section portfolio is given to fulfill the diversified and innovative investment needs of investors. The industries included are car industry, biopharmaceutical industry and financial service industry. Furthermore, the results reflect the actual situation to a large extent, including the weakness in the US market in December 2018 due to uncertain Fed policy and the impact of the COVID-19 in 2020. In this article, an Intra-Industry analysis based on the net asset values of the three targeted industries will be carried out first, then the Macro analysis will be conducted based on the optimal portfolio of the three industries. A conclusion of the findings is included at the end of the article.
\end{abstract}

\section{INTRODUCTION}

In recent years, the risk of world financial market has gradually increased with the turbulence of world situation. For example, since 2016, Brexit has brought great uncertainty to the global financial market, especially to the European financial market [1]. Besides, the Sino US trade war has also cast a shadow over the two most powerful countries in the world, and the entire global financial market has also suffered from its huge negative impact [2]. The outbreak of the endemic in the first half of 2020 makes the world's economy depressed and the investment market more uncertain [3]. The market generally predicts that the COVID- 19 pandemic will bring disastrous consequences to the U.S. economy [4]. At the same time, some researchers believe that the impact of the pandemic on the overall economy of the United States is moderate [5]. However, in any case, the COVID-19's outbreak will bring great uncertainty to the U.S. economy. How the market is affected by these factors, and, at the same time, how to select reasonable asset investment in this highly risky market, are the problems that this article focuses on.

Investment is a magic art between what people firstly devoted and what people finally gained. Normally, the investors who are in securities and other risky assets need to resolve the core problems of " $2 \mathrm{R}$ "-Risk and Return. It is obviously that investors should consider the expected return and risk when they make decisions on investment, and they should find a balance between " $2 \mathrm{R}$ ", so that they can earn the profit for certainty. Hicks pointed out two aspects of the impact of risk factors on investment [6]. First, risk can affect the expected investment period. Second, it will affect the expected return on investment. In Hicks's "Separation Theorem", he tried to explain the need for currency because of investors' desire for high return and low risk [7]. Williams who put forward the "Dividend Discount Model", used the idea of discount to deal with the problem of uncertainty. Williams' method of equity valuation decision to weigh returns and risks ignored benefits of diversification [8]. Leavens argued for the benefits of decentralization. Von Neumann then applied the concept of expected utility to propose a decision-making method under uncertain conditions [9].

On the basis of previous theories, Markowitz's portfolio theory was born in the 1950s, highlighting the area of investment under risk and uncertainty [10]. The main idea of traditional Markowitz portfolio theory is "Native Diversification", which means that "The greater the number of assets in a portfolio, the greater the risk of diversification." and "Don't put all your eggs in one basket." [11], while Modern Markowitz Portfolio Theory is a mathematical framework for portfolios that maximizes expected returns for a given level of risk. In this model, risk is the standard deviation of the portfolio return. Even though the Markowitz model requires a huge number of data to fill the covariance matrix, it will provide the most accurate results, once people's valuations and raw data with precise calculation. And it has more superior theoretic and realistic values than other models. In Markowitz's model, the optimal portfolio is determined by selecting the portfolio, which has the highest Sharpe ratio, and then, the changes of the optimal

3303203578@qq.com bkuroyuki@udel.edu chui.li2@student.unsw.edu.au 
portfolio's asset ratio are analyzed in different periods to explore the relative performance of each asset more [12].

Car industry, biopharmaceutical industry and financial service industry are selected as the targeted industries in this paper for the portfolio analysis, with their close pricing ranging from January 2016 to June 2020. Based on the fact that these three sectors account for large shares in the U.S. market, this selection is a good sample of the overall state of the American economy over the whole period. The biopharmaceutical industry plays an important role in fighting against the COVID-19, and it also plays an important role in other periods to provide solutions to treat other diseases. Since biopharmaceutical industry is an important industry and it has a lot to do with the COVID-19, the stock of it is analyzed to show its stability of performance. The financial services sector encompasses a wide range of businesses, such as investment, lending, insurance, securities trading and issuance, asset management and foreign exchange activities [13]. The influences of major events on financial service industries can be well reflected by its stock performance, since it faces many challenges, like the need for shelter in place and distant socialing, meaning that few customers are served in physical branches. This impact put additional pressure on channels, such as phone support, online and social media when these events occurred [14]. Furthermore, car industry is selected because it is a completely different industry, compared with the other two industries. Its reaction to the major events is also discussed to see if its performance is as expected.

\section{METHOD \& DATA}

\subsection{Data}

Fifteen companies are selected as the leading enterprises, who have the highest market value in its industry. Five leading enterprises are used as representatives of each industry. These three representative industries can partially reflect the overall condition of the U.S. economy industries and whether their stock performance is sensitive to the major events. Besides, since they are completely different industries, the investment portfolio analysis of them can provide with more practical investing advice and ideas for the investors, to achieve their diversified investing needs

The full name of the company abbreviation of each industry is as follows:

\section{Car Industry:}

GM- General Motors Company

HMC- Honda Motor Co Ltd

RACE- Ferrari NV

TM- Toyota Motor Corp

TSLA- Tesla Inc

\section{Biopharmaceutical Industry:}

DXCM- DexCom, Inc.

JNJ- Johnson \& Johnson

LLY- Eli Lilly And Co
MRK- Merck \& Co., Inc.

NVS- Novartis AG

Financial Service Industry:

AXP- American Express Company

DFS- Discover Financial Services

GPN- Global Payments Inc

MA- Mastercard Inc

SYF- Synchrony Financial

\subsection{Method}

The Markowitz model is modified to calculate the optimal portfolio based on the closing price data of above three kinds of industries from January 2016 to June 2020. This model is divided into three time periods as 2016.12017.12, 2018.1-2019.12 and 2020.1-2020.6.

The Markowitz model used is as follows:

$$
\text { s.t. }\left\{\begin{array}{c}
E\left(R_{\omega}\right)=\omega^{T} E(R)=M \\
l^{T} \omega=1, \quad \omega_{i} \geq 0, \quad i=1,2, \ldots, n \\
\min \sigma_{\omega}^{2}=\omega^{T} \sum \omega
\end{array}\right.
$$

$\sigma_{\omega}^{2}$ represents the variance of portfolio returns.

$\omega=\left(\omega_{1}, \omega_{2}, \ldots, \omega_{n}\right)$ is the weight vector of the portfolio in the portfolio. $\Sigma=\left(\sigma_{i j}\right)_{n \times n}$ is the covariance matrix of the portfolio. $i$ and $j$ represent type $i$ and $\mathrm{j}$ assets, respectively. $\mathrm{M}$ is the expected rate of return. $l^{T}=(1,1, \ldots, 1)_{1 \times n}$

\section{RESULTS \& DISCUSSION}

Based on the calculation of Model 1, the efficient frontiers of each stage are depicted firstly and the combination is selected as the highest Sharpe ratio. Secondly, a comparison of the returns of the portfolio and the stocks of the separate investment industry is illustrated.

\subsection{Efficient Frontiers}

After the Markowitz model is applied, the efficient frontiers of the three stages are shown in following figures: 


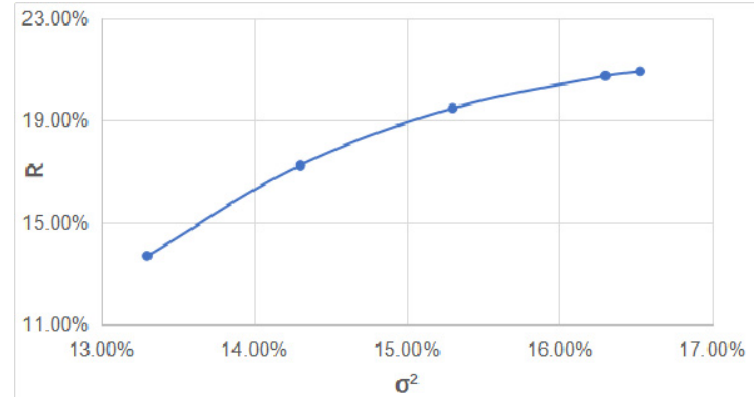

Figure 1. 2016-2017 Efficient Frontiers.

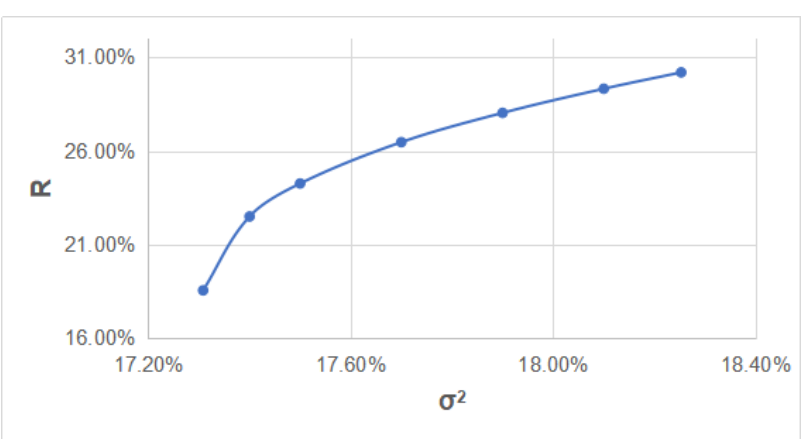

Figure 2. 2018-2019 Efficient Frontiers

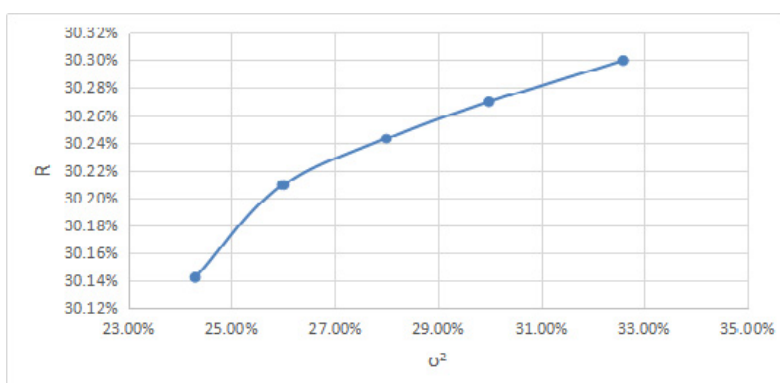

Figure 3. 2020 Efficient Frontiers.

It can be found that compared with the effective frontiers of 2018-2019, the effective frontier in 2020 has obviously shifted to the right. This also shows that under the same rate of return, compared with 2018-2019, the risk of portfolio in 2020 has increased significantly.

\subsection{Intra-Industry Analysis}

Based on the Efficient Frontiers shown above (Figure 13 ), the optimal portfolio for each time period is selected with the largest proportion of sharpness of the curve, respectively. The optimal portfolios are shown in Table below.

Table 1. PORTFOLIO WITH MAXIMUM SHARP RATIO

\begin{tabular}{llll}
\hline & $2016-2017$ & $2018-2019$ & $2020.1-$ \\
& & & 2020.6 \\
\hline Financial Service & $95.70 \%$ & $0.00 \%$ & $0.00 \%$ \\
Car & $4.30 \%$ & $0.00 \%$ & $19.72 \%$ \\
Biopharmaceutical & $0.00 \%$ & $100.00 \%$ & $\mathbf{8 0 . 2 8 \%}$ \\
Sharpe ratio & 1.273 & 1.654 & 1.241 \\
\hline
\end{tabular}

\subsection{Micro Analysis}

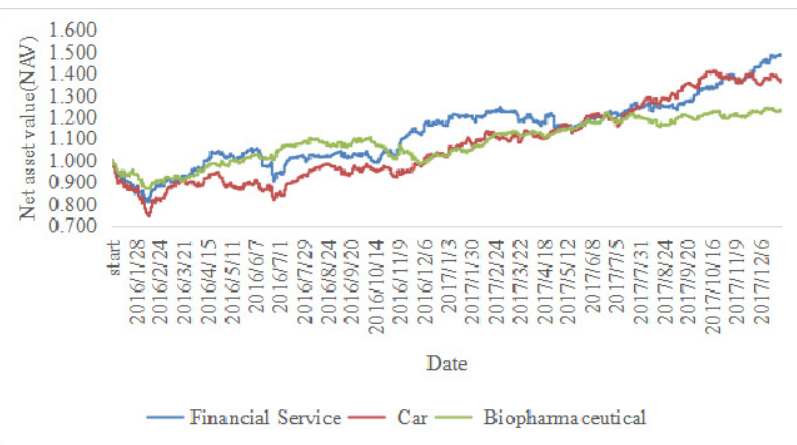

Figure 4. 2016-2017 NAV trends of the three industries *'NAV' stands for Net asset value

In Micro Analysis, Net asset value (NAV) is introduced to explicate capital situation between industries. NAV can be defined as the value of a company's assets minus any liabilities and expenses. Basically, the NAV represents the price at which investors can buy or sell units of the fund. Generally, when the value of the securities in the fund increases, the NAV increases.

As seen in Figure 4, the car and financial service industries has overall more significant increases in NAV, compared with pharmaceutical industry during the period from 2016 to 2017. Biopharmaceutical industry has a relatively flat trend, compared with the other industries. It should be noted that even though the car industry had the lowest NAV compared with the other two industries at the beginning of 2016, it grew steadily throughout the two-year period, and even had the largest number in NAV in October 2017.

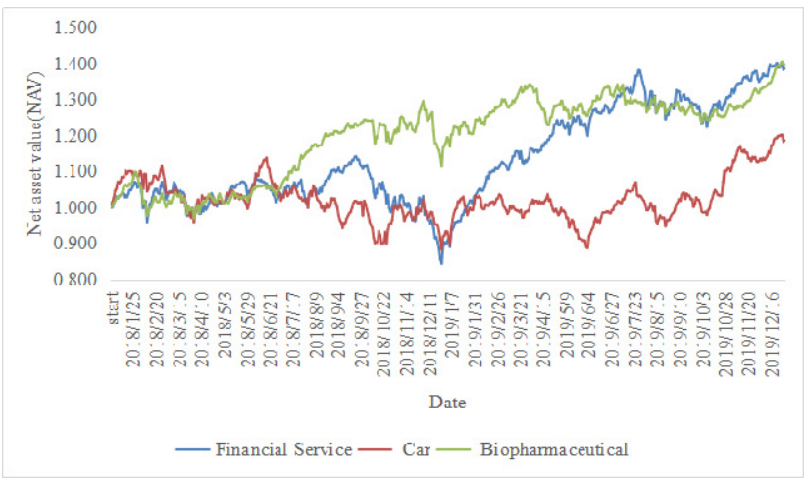

Figure 5. 2018-2019 NAV trends of the three industries.

The Figure 5 above shown that all of the three industries experienced a decrease in NAV in December 2018. Much of the weakness in the US market in December 2018 has been down to worries about the future path of Fed policy. Other factors like tariffs driving uncertainty, big tech under scrutiny and inflated company earnings were considered as well [15]. The economic conditions of the three industries have been affected by this economic environment, which were reflected in the declines of NAV. The stock of Biopharmaceutical on average had the highest NAV among the stocks of the three industries and it has outperformed the previous year. On the contrary, the car 
industry's performance was down from last period since it had the lowest number among the three industries, starting from $23^{\text {rd }}$ January 2019 to the end of the current period, and it had the lowest NAV in average among the three industries.

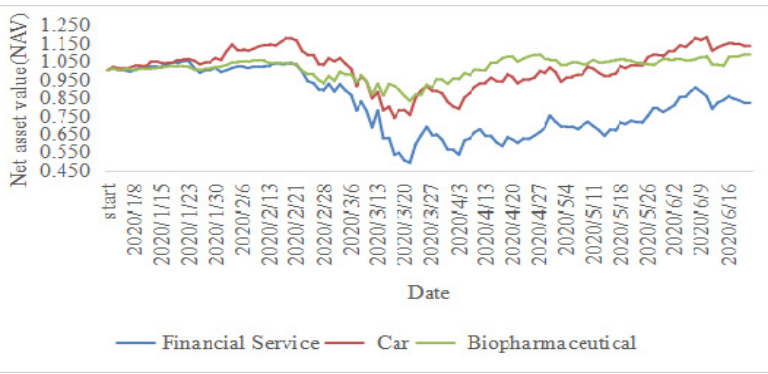

Figure 6. $2020 \mathrm{NAV}$ trends of the three industries.

The Figure 6 explained that even though the numbers of NAV for the biopharmaceutical and financial service industries at the beginning of 2020 were dropped, compared with those of the ending period from last year, the trend of the three industries were nearly constant with less volatility before $24^{\text {th }}$ February, 2020. After that, the COVID-19's outbreak devastated the world economy, including the economy of America. NAV values were gradually rising in all three industries after the value of securities in three industries bottomed out on March 23, 2020. Furthermore, financial service industry had the lowest NAV in average among the three industries and its NAV value even dropped to 0.491 on March 23, 2020, which was the most significant decline among the three sectors. This was maybe because that the outbreak has shut down a large number of brick-and-mortar stores and service businesses, undoubtedly reducing many channels to sell goods and services [16]. As many families were struggled to make ends meet as a result of the virus, their appetite for consuming obviously waned. As a result, the value of securities of the financial service industry would decline significantly. The biopharmaceutical and car industry were not as affected by the outbreak as consumer industry, so over time the NAV values of these two industries nearly returned to their reasonable levels.

\subsection{Macro Analysis}

Through Markowitz model, the optimal portfolio of three industries is calculated, and the portfolio is used to invest in the corresponding year. The NAV trends of best position and three industries is as follows (the initial NAV is set as 1):

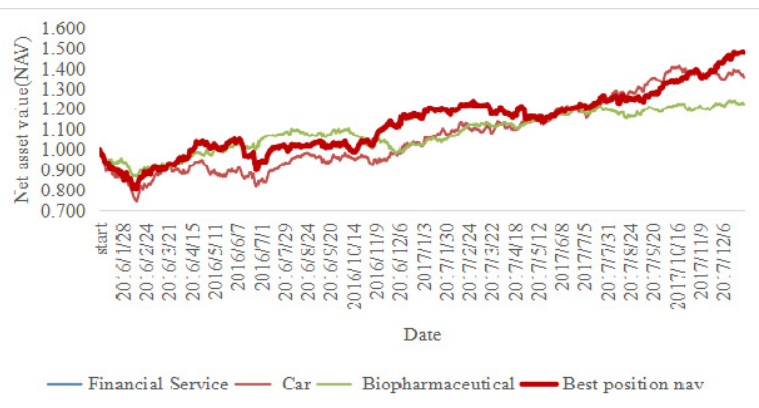

Figure 7. 2016-2017 Best Position NAV.
According to Figure 7, from 2016 to 2017, the NAV of the optimal portfolio rose steadily from the first 1 to 1.48 at the end of 2017, with an annual earnings number of $20.75 \%$, at a high level. At the same time, the volatility is $16.30 \%$, which shows that the overall performance of assets is stable. From the performance of this portfolio, it is seen that the economic performance of the United States from 2016 to 2017 should be stable and rising, with excellent overall performance.

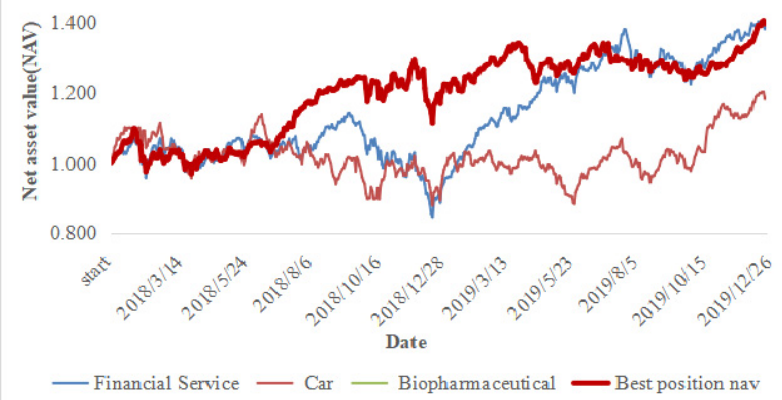

Figure 8. 2018-2019 Best Position NAV.

According to Figure 8, from 2018 to 2019, the NAV of the optimal portfolio increased from 1 to 1.4, with an annualized yield of $29.32 \%$, higher than that of 16 to 17 years. But correspondingly, the volatility increased from $16.30 \%$ to $18.10 \%$. Therefore, from these data, a preliminary conclusion could be drawn, which is from 2018 to 2019 , the U.S. economy shows an upward trend, but it is more instability than that from 2016 to 2017 . Combined with the actual situation, this may be due to the negative impact of the Sino US trade war, supported by the sharp fluctuation of NAV in September 2018.

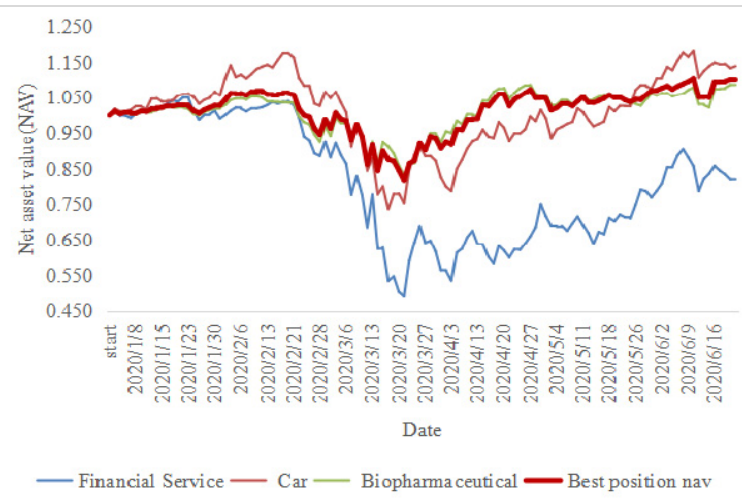

Figure 9. 2020 Best Position NAV.

According to Figure 9, from 2020 to present, the performance of the portfolio has changed greatly compared with the previous two periods. The NAV of the optimal portfolio rose only from 1 at the beginning of 2020 to 1.102 in June 2020 , but it has a volatility of $30.0 \%$, which fully reflects that the overall economy of the United States is not performing well in 2020 compared with previous years. The market faces a lot of risks.

This Figure 9 also shows that the COVID-19 has a huge impact on the overall economy of the United States, making the economy of the United States get into a greater risk, and the value of investment has declined. At 
the same time, the U.S. stock market disaster in March exacerbated the negative impact of the pandemic of COVID-19 on the economy.

In short, in the first half of 2020, the risk of US stock market increased. The investment value decreased, and the overall economic performance was poor.

\section{CONCLUSION}

In the context of the current fluctuate situation, such as the trade war and the pandemic of COVID-19, investors are facing the dilemma of how to balance the risk and return. To address this issue, the Markowitz model is used to analyze the economic trend with the data of three industries with a long extent from 2016 to 2020. At the same time, in order to achieve the purpose of risk diversification and diversification, new cross industry portfolio is selected, including car industry, biopharmaceutical industry and financial service industry. Based on these three targets, this paper analyzes the economic situation and some other industries in the United States. In the research process, the return of the optimal portfolio during a long period (2016-2020) is used to reflect the general trend of the U.S. economy in recent years. Such a long period of data will bring better reference value to investors. Secondly, we analyzed the performance of the three industries and use them to form a cross industry portfolio, trying to find an excellent and stable investment way for investors. Besides, it is found that the pharmaceutical industry is always performing very well, despite the overall poor performance of the market. Combined with the actual situation, this industry is supposed to be one of the most worthwhile industries for investors. This research has reference value for investors who want to make a return on their investment, even if the overall economic situation is not doing well due to the epidemic. In the discussion, it is noticed that the performance of the car industry in the pandemic stage was not poor, which was different from the initial expectation. In the future, more in-depth research on cars may be carried out, and the research scope would be expanded to more industries.

\section{REFERENCES}

[1] Holly Ellyatt. (2019). What Brexit could mean for the US economy.

[2] Dan Steinbock. (2018). U.S.-China Trade War and Its Global Impacts.

[3] Nuno Fernandes. (2020). Economic Effects of Coronavirus Outbreak (COVID-19) on the World Economy.

[4] Jay Shambaugh. (2020). COVID-19 and the US economy: FAQ on the economic impact \& policy response. Brookings.

[5] Efraim Benmelech, C. F. (2020). The 1918 influenza did not kill the US economy | VOX, CEPR Policy Portal. VoxEU.

[6] Arthur E. Gooding. (1975). Quantification of investors' perceptions of common stocks: risk and return dimensions.

[7] Poitras, G. (2010). Valuation of equity securities: History, theory and application. In Valuation of Equity Securities: History, Theory and Application. World Scientific Publishing Co.

[8] Markowitz, H. M. (2009). Harry Markowitz (Vol. 1). WORLD SCIENTIFIC.

[9] Markowitz, H. M. (1999). The Early History of Portfolio Theory: 1600-1960. Financial Analysts Journal, 55(4), 5-16.

[10] Beattie, A. (2020). Understanding the History of the Modern Portfolio.

[11] Ruedi, P. (2017). Diversification: The oldest trick in the investment book.

[12] Francis, J. C., \& Kim, D. (2013). Modern Portfolio Theory: Foundations, Analysis, and NewDevelopments.576.

[13] Mark Kolakowski. (2019). The Financial Services Industry for Beginners. Thebalancecareers.

[14] Rebecca Sentance. (2020). How is coronavirus impacting the financial sector - and how are brands responding? - Econsultancy Econsultancy.

[15] Frazee, G. (2018). 6 factors that fueled the stock market dive in 2018.

[16] Howland, D. (2020). Brick and mortar's next chapter. 